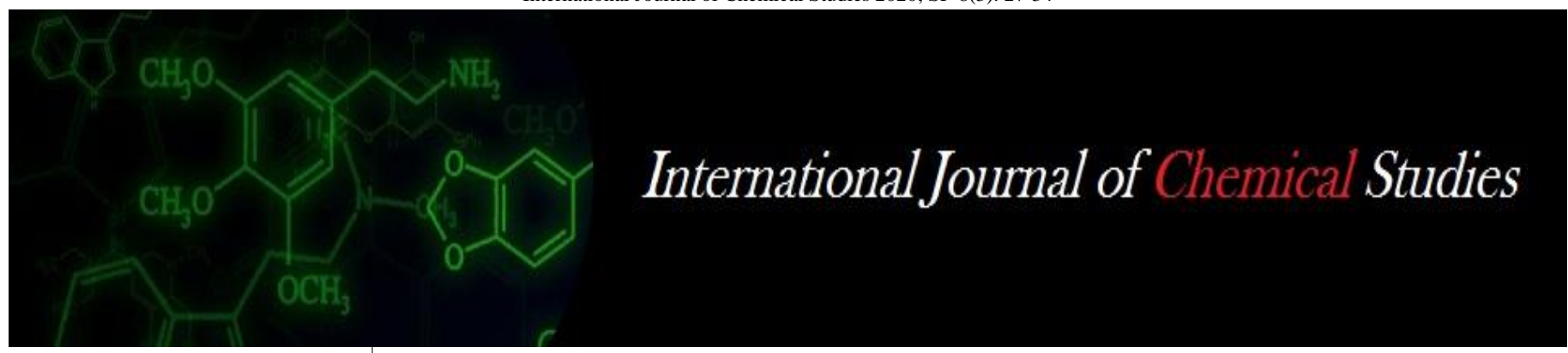

P-ISSN: 2349-8528

E-ISSN: 2321-4902

www.chemijournal.com

IJCS 2020; SP-8(3): 27-34

(C) 2020 IJCS

Received: 16-03-2020

Accepted: 17-04-2020

\section{DJ Talukdar}

Assistant Professor, Department

of Animal Reproduction,

Gynaecology and Obstetrics,

College of Veterinary Sciences

and A. H., Central Agricultural

University, Selesih, Aizawl,

Mizoram, India

\section{Papori Talukdar}

Assistant Professor, Department

of Animal Nutrition, College of

Veterinary Science, Assam

Agricultural University,

Khanapara, Assam, India

DK Murasing

M.V.Sc. Scholar, Department of Animal Reproduction,

Gynaecology and Obstetrics,

College of Veterinary Sciences

and A. H., Central Agricultural

University, Selesih, Aizawl,

Mizoram, India

\section{A Kayina}

M.V.Sc. Scholar, Department of Animal Reproduction,

Gynaecology \& Obstetrics,

College of Veterinary Sciences \&

A.H., Central Agricultural

University, Selesih, Mizoram,

India

\title{
Brucellosis in India: An overeview
}

\section{DJ Talukdar, Papori Talukdar, DK Murasing and A Kayina}

\author{
DOI: https://doi.org/10.22271/chemi.2020.v8.i3a.9802
}

\begin{abstract}
Brucellosis is one of the most important and widespread zoonotic disease in the world. Animals may transmit Brucella organisms during septic abortion, during slaughter, and through their milk. Brucellosis is rarely transmitted from person to person. The incidence of brucellosis in human is closely tied to the prevalence of infection in animals, and to practices that allow exposure of humans to potentially infected animals or their products. B. abortus, B. melitensis, B. suis, B. canis, and marine mammal Brucella species are human pathogens. Brucellae can enter mammalian hosts through skin abrasions or cuts, the conjunctiva, the respiratory tract, and the gastrointestinal tract. Bison, elk, reindeer and caribou can be infected with Brucella spp., but their role in transmission of the infections to livestock remains under debate. The uncomplicated cases should be treated with doxycycline, streptomycin and rifampicin. Mass vaccination is crucial for the control and eradication of bovine, ovine and caprine brucellosis. Complementary measures that may need to consideration like improved farm hygiene, restriction and control of trade and movement of animals, testing of animals and isolation and removal of infected animals.
\end{abstract}

Keywords: Brucellosis, India, prevalence, pathogenesis, clinical manifestation

\section{Introduction}

According to the Food and Agriculture Organization (FAO), the World Health Organization (WHO) and the Office International des Epizooties (OIE), brucellosis is still one of the most important and widespread zoonoses in the world. Infections are caused by various bacteria of the genus Brucella, which tend to infect a specific animal species. However, most species of Brucella are able to infect other animal species as well and some of them have zoonotic potential. In humans, brucellosis can be caused by B. abortus, B. melitensis, B. suis biovars 1-4 and, rarely, B. canis or marine mammal Brucella. B. ovis, B. neotomae, and B. suis biovar 5 have not been associated with human disease. The disease affects cattle, swine, sheep and goats, camels, equines, and dogs. It may also infect other ruminants and marine mammals. A new strain, named Brucella microti, was recently isolated from the common vole (Microtus arvalis) in Central Europe ${ }^{[1]}$. Brucella pinnipediae and cetaceae are also newly recognized marine mammal Brucellae that may also be human pathogens ${ }^{[2,3]}$.

In 1887 David Bruce, for whom the genus Brucella is named, isolated the causative organism from the spleens of five patients who died from the disease and placed the microorganism within the genus Micrococcus. Ten years later, ML Hughes, who coined the name "undulant fever," published a monograph that detailed clinical and pathological findings in 844 patients [4].

That same year, Danish investigator B Bang identified an organism, which he called the "bacillus of abortion," in the placentas and fetuses of cattle suffering from contagious abortion. In 1917 AC Evans recognized that Bang's organism was identical to that described by Bruce as the causative agent of human brucellosis. The organism infects mainly cattle, sheep, goats, and other ruminants, in which it causes abortion, fetal death, and genital infections [5, 6]. Humans, who are usually infected incidentally by contact with infected animals or ingestion of dairy foods, may develop numerous symptoms in addition to the usual ones of fever, malaise, and muscle pain.

\section{Infectious agent}

Brucellae are small, nonmotile, nonsporulating, nontoxigenic, nonfermenting, facultative, intracellular, gram-negative coccobacilli.
Corresponding Author: Assistant Professor, Department of Animal Reproduction, Gynaecology and Obstetrics, College of Veterinary Sciences and A. H., Central Agricultural University, Selesih, Aizawl, Mizoram, India 


\section{Epidemiology}

Animals may transmit Brucella organisms during septic abortion, during slaughter, and through their milk ${ }^{[7]}$. Brucellosis is rarely, if ever, transmitted from person to person. The incidence of human disease is thus closely tied to the prevalence of infection in sheep, goats, and cattle, and to practices that allow exposure of humans to potentially infected animals or their products. In the United States, where most states are free of infected animals and where dairy products are routinely pasteurized, illness occurs primarily in individuals who have occupational exposure to infected animals, such as veterinarians, shepherds, cattlemen, and slaughterhouse workers. In many other countries, humans more commonly acquire infection by ingesting unpasteurized dairy products, especially cheese.

\section{Pathogenesis}

Brucellae can enter mammalian hosts through skin abrasions or cuts, the conjunctiva, the respiratory tract, and the gastrointestinal tract ${ }^{[8]}$. In the gastrointestinal tract, the organisms are phagocytosed by lymphoepithelial cells of gutassociated lymphoid tissue, from which they gain access to the submucosa [9]. Organisms are rapidly ingested by polymorphonuclear leukocytes, which generally fail to kill them $[10,11]$ and are also phagocytosed by macrophages. Bacteria transported in macrophages, which travel to lymphoid tissue draining the infection site, may eventually localize in lymph nodes, liver, spleen, mammary glands, joints, kidneys, and bone marrow.

In macrophages, brucellae inhibit fusion of phagosomes and lysosomes ${ }^{[12]}$ and replicate within compartments that contain components of endoplasmic reticulum [13] via a process facilitated by the type IV secretion system ${ }^{[14]}$. If unchecked by macrophage microbicidal mechanisms, the bacteria destroy their host cells and infect additional cells. Brucellae can also replicate extracellularly in host tissues. Histopathologically, the host cellular response may range from abscess formation to lymphocytic infiltration to granuloma formation with caseous necrosis.

In ruminants, Brucella organisms bypass the most effective host defenses by targeting embryonic and trophoblastic tissue. In cells of these tissues, the bacteria grow not only in the phagosome but also in the cytoplasm and the rough endoplasmic reticulum ${ }^{[15]}$. In the absence of effective intracellular microbicidal mechanisms, these tissues permit exuberant bacterial growth, which leads to fetal death and abortion. In ruminants, the presence in the placenta of erythritol may further enhance growth of brucellae. Products of conception at the time of abortion may contain up to $10^{10}$ bacteria per gram of tissue ${ }^{[16]}$ When septic abortion occurs, the intense concentration of bacteria and aerosolization of infected body fluids during parturition often result in infection of other animals and humans.

\section{Prevalence of brucellosis Global scenario}

The brucellosis which has been known like Malta fever, undulant fever, Rock of Gibraltar fever and Bang's disease has very old history, as organisms resembling Brucella had been detected in carbonized cheese from the Roman era. Brucellosis was first recognized as a disease affecting humans on the Island of Malta in the early 20th century. Though its distribution is worldwide; yet brucellosis is more common in countries with poorly standardized animal and public health programme ${ }^{[17]}$. The routes of infection are multiple i.e., food- borne, occupational or recreational, linked to travel and even to bioterrorism. New Brucella strains or species may emerge and existing Brucella species adapt to changing social, cultural, travel and agricultural environment ${ }^{[18]}$. The incidence of reactors in newly established cattle farms may be more than $30 \%$, however, the highest rate $(72.9 \%)$ of infection till now has been reported in the Palestinian Authority ${ }^{[19]}$. It is interesting to note that the second highest prevalence $(71.42 \%)$ of brucellosis has been reported in mules from Egypt ${ }^{[20]}$. Invariably, all domestic animals suffer from this disease. Brucellosis in buffaloes has been reported from Egypt $(10.0 \%)$ and Pakistan $(5.05 \%)^{[20]}$. Since cattle are found through out the world, prevalence of brucellosis $(0.85$ to $23.3 \%$ ) in cattle has been reported from a wide range of countries ${ }^{[21]}$. In camels, brucellosis has been reported from Arabian and African countries (0.0- 17.20\%), where the disease also occurs in buffaloes, equines and swine ${ }^{[6]}$. Variable prevalence of this disease has been reported in sheep and goats. Bio varieties of Brucella vary with respect to geographic region. Br. melitensis biovar 1 from Libya, Oman and Israel and Br. melitensis biovar 2 from Turkey and Saudi Arabia have been isolated. Br. melitensis biovar 3 isthe most commonly isolated species from animals in Egypt, Jordan, Israel, Tunisia and Turkey ${ }^{[21]}$. Br. abortus biovar 1 in Egypt, biovar 2 in Iran, biovar 3 in Iran and Turkey and biovar 6 in Sudan have been reported ${ }^{[22]}$. The countries with the highest incidence of human brucellosis include Saudi Arabia, Iran, Palestinian Authority, Syria, Jordan and Oman. Bahrain is reported to have no incidence ${ }^{[21]}$. The percent prevalence of bovine brucellosis has been reported to decrease in Ireland and Italy during the year 1999-2000 but there had been a trend towards a significant increase in Azores ${ }^{[23]}$.

\section{Indian scenario}

Brucellosis is an economically important disease of wild and domestic animals and it is particularly important in Indian context which is the largest producer of milk in the world and enriched reservoir of varieties of bovine species. Although it is very crucial for the economy of developing country like India, but regular monitoring of brucellosis in animals have received no attention till date. Bovine brucellosis is widespread in India and appears to be on the increase in recent times, perhaps due to increased trade and rapid movement of livestock [24]. The natural service of the livestocks in rural areas is perhaps yet another important factor in the maintenance and spread of infection. Free grazing and movement with frequent mixing of flocks of sheep and goats also contribute to the wide distribution of brucellosis in these animals. Chahota et al. ${ }^{[25]}$ have reported a severe outbreak of brucellosis in an organized dairy farm leading to abortions, retained placenta and still birth in cows. Mathur [26] reported $8.5 \%$ sero-prevalence of brucellosis among dairy personnel in contact with infected animals. In a separate study carried out by Mathur [27] in Haryana, concluded the goats and sheep as the sources of human infection by isolating $B$. melitensis as a predominant strain from human blood as well as milk samples from goats and sheep. As many as $4.2 \%$ aborted women were seropositive for the disease ${ }^{[28]}$. In Gujarat, $8.5 \%$ prevalence of Brucella agglutinins was recorded in human cases ${ }^{[29]}$. The study conducted by Thakur and Thapliyal ${ }^{[30]}$, revealed a prevalence rate of $4.97 \%$ in samples obtained from persons exposed to animals. The much higher seroprevalence rate has been also noted in specific risk groups such as abattoir workers [31, 32]. The study which was carried out by Bandyopadhyay et al., ${ }^{\text {[33] }}$ 
in yaks of North-Eastern hilly yak tracts of Arunachal Pradesh of India to explore the seroprevalence of brucellosis in yaks and $23.79,21.11$ and $18.98 \%$ were found positive for brucellosis using avidin-biotin ELISA (AB-ELISA), RoseBengal plate test (RBPT) and standard tube-agglutination test (STAT), respectively. The alarming prevalence as recorded was highest among the yak cows (31.42\%) followed by heifers $(23.85 \%)$ and bulls $(8.88 \%)$. Rajkhowa et al., [34] studied on the seroprevalence of brucellosis in mithuns maintained at the National Research Centre on Mithun, Nagaland, India revealed that the number of animals found positive for brucellosis in avidin-biotin enzyme-linkedimmunosorbent assay, standard tube-agglutination test and Rose-Bengal plate test were 34, 20 and 11\%, respectively.

\section{Clinical manifestations of brucellosis \\ Brucellosis in Cattle}

Brucellosis in animals is generally typified by late-term abortions and inflammatory lesions in the male reproductive tract. Bovine brucellosis is usually caused by $B$. abortus which has seven different biovars, named 1, 2, 3, 4, 5, 6 and 9. Biovar 1 is the most important and widespread B. abortus biovar. Among 530 B. abortus samples isolated from humans and animals in Latin America from 1968 to 1991, 399 $(75.3 \%)$ were biovar 1 and most of them were isolated from cattle ${ }^{[35]}$. Natural infection with other Brucella species is rare. In areas where B. melitensis infection is enzootic in small ruminants, it is rarely seen abortion in cattle even though some infected animals may become carriers and excrete the bacteria in the milk ${ }^{[6,36]}$. Dafni et al. ${ }^{[37]}$ described foci of $B$. melitensis infection in cattle in Israel, but the occurrence of abortion was not confirmed. B. suis infection in cattle is selflimiting and thus it is not sustained ${ }^{[38]}$.

Sexually mature females are more susceptible to B. abortus infection than bulls ${ }^{[6]}$. This susceptibility increases during pregnancy, and animals get more susceptible with the advance of pregnancy ${ }^{[39,40]}$. B. abortus infection in calf is self-limiting [41].

The period of incubation varies considerably and it is mainly influenced by gestation, exposure dose, age, and vaccination [6]. The length of the incubation period is inversely proportional to the stage of gestation at the time of exposure. Bang ${ }^{[42]}$ observed an abortion in a three-month pregnant heifer 56 days after feeding her with the cotyledons from an aborting cow. Other experimental studies have shown incubation periods varying from 53 to 251 days ${ }^{[43]}$.

The major clinical sign in pregnant females is abortion in bovine and buffalo cows ${ }^{[40]}$. Abortion usually occurs from the 5 th to the 8th month of gestation ${ }^{[36]}$. The occurrence of abortion is related to some factors, such as the stage of pregnancy, the number of infecting organisms and the animal resistance [6]. Bang [42] observed that infected pregnant females usually abort only once, and concluded that infected cows acquire immunity. Alternatively to abortion, premature, stillborn or weak calves may occur. Abortion is often followed by placental retention and metritis, which may cause permanent or transient infertility ${ }^{[44]}$.

Brucellosis does not usually result gross organic lesions $[45,46]$ but sometimes a mild interstitial inflammatory reaction in the mammary gland may be observed ${ }^{[47]}$ which is associated with elimination of bacteria in the milk. Mammary gland macrophages may provide the intracellular environment for the persistence of $B$. abortus in the mammary gland of chronically infected cows ${ }^{[12]}$.
Despite being susceptible to the infection ${ }^{[48]}$ no clinical signs have been observed in infected heifers at prepubescent stage. Edgington and Donham [49] reported that 15 heifers experimentally infected with $B$. abortus before breeding failed to abort during the subsequent pregnancy, but there are evidences that heifers infected before adulthood may abort and contribute to maintain the infection in the herd ${ }^{[36]}$.

The pathogenic action of $B$. abortus infection in bulls has long been established. Buck et al. ${ }^{[50]}$ isolated it from bulls with seminal vesiculitis and/or orchitis. Infection of the reproductive tract may leads to orchitis, epididymitis, ampullitis and seminal vesiculitis. Orchitis is occasionally manifested, and when it occurs it is usually unilateral, but both testicles may be affected. Scattered foci of necrosis coalesce to produce total testicular necrosis ${ }^{[51]}$. Atrophy of testicle may also occur ${ }^{[52]}$. The syndrome involving seminal vesicles and ampoule is apparently more common than the one involving the testicles and epididymides ${ }^{[53]}$.

Brucellosis may result in fetal pneumonia, and to the naked eye the only recognizable lesion is a consolidation of the lungs associated with a grayish mottling in a certain number of fetuses ${ }^{[54]}$. Nevertheless not all the brucellosis aborted fetuses have pneumonia, and lung lesions are not specific enough to enable us to incriminate $B$. abortus as the cause of abortion ${ }^{[55]}$. Others gross lesions are also frequently described in aborted fetuses. Xavier et al. ${ }^{[47]}$ observed that cows that were experimentally infected with $B$. abortus presented either weak newborn calves or aborted fetuses with mild peritonitis and abdominal organs covered with a small amount of fibrinous exudate, and such exudates was also found in their pericardium.

\section{Brucellosis in pigs}

$B$. suis is the only species that causes systemic infection leading to reproductive problems in the swine. Swine can be infected by other Brucella species but the infection is invariably self-limiting ${ }^{[56]}$.

Clinical signs of $B$. suis infection in the swine vary considerably, depending on the animal age, previous exposure, and the organ involved ${ }^{[57]}$. Manifestations of swine brucellosis are abortion, birth of weak piglets, infertility, orchitis, epididymitis, spondylitis of especially the lumbar and sacral regions, arthritis, paralysis of hindlimbs, and lameness, but many infected herds may have no signs. There is no pyrexia, and death is rare ${ }^{[56]}$. Abscesses of different sizes frequently occur in organs and tissues ${ }^{[44]}$.

The rate of abortion is higher in sows or gilts exposed to $B$. suis via the genital tract at the time of breeding. Abortions may occur at any time and are influenced more by the time of exposure to the $B$. suis rather than by the stage of gestation [56]. Abortions have been observed as early as 17 days following natural insemination by boars disseminating $B$. suis in the semen. Early abortions are usually unnoticed by the owner, and the only evidence of infection is that the sow displays signs of estrus 30 to 45 days after mating. Little or no vaginal discharge is observed in early abortions. Abortions that occur during mid or late stages of gestation are usually associated with females that acquire infection after 35 to 40 days of pregnancy ${ }^{[57]}$. Affected sows rarely have a second abortion, and females infected before sexual maturity hardly ever abort ${ }^{[44]}$. Clinically apparent abnormal vaginal exudate is seldom observed in sows that have uterine infection ${ }^{[56]}$.

Some infected boars do not develop a localized genital infection. However, boars that do develop genital infection seldom recover from it. Infertility and lack of sexual activity 
may occur in infected boars and is frequently associated with testicular involvement. More commonly, boars have infections in their accessory genital glands; however this does not necessarily reduce fertility ${ }^{[56]}$. Infection of the genital organs lasts for a shorter period of time in the female than in the male ${ }^{[44]}$.

The disease is more common in adults. Clinical evidence of brucellosis in suckling and weaning piglets is usually absent. Clinical manifestations of arthritis and lameness or spondylitis associated with paralysis of hindlimbs are occasionally observed in any age of swine ${ }^{[56]}$.

\section{Brucellosis in sheep and goats}

Brucellosis in sheep and goats are mainly caused by $B$. melitensis and B. ovis. However, other types of Brucella can infect sheep and goats. B. abortus was isolated from eight sheep and from their offspring over a period of 40 months. $B$. suis was isolated from the semen of a ram ${ }^{[53,58]}$.

Brucella infection produces a chronic disease on sexually mature animals, being the genital tract the main target of the bacteria. B. melitensis affects both species, being abortion in females the main clinical sign, whereas $B$. ovis affects only sheep and it is the cause of contagious epididymitis of rams [59]. The effect of the disease at flock level is characterized by a general decrease in flock fertility, an increase in lamb/kid mortality with a low weaning percentage, a decrease on milk production and an increased culling of males due to chronic lesion on reproductive organs ${ }^{[60,61]}$

\section{Brucellosis in horses}

The infection is caused by $B$. abortus and occasionally $B$. suis. The disease is acquired through contact with infected cattle or swine, ingestion of contaminated food or water and via penetration of the skin or mucous membrane. Brucellosis in horses can either remain asymptomatic or it can be associated with clinical disease ${ }^{[62]}$.

Experimental infection with $B$. abortus in horses induced only mild pyrexia. However, granulomatous lesions were observed in lung, liver, testes and metatarsophalangeal synovial membranes. The mares bred normally without abortion or other signs ${ }^{[63]}$. The disease is mainly recognized as an inflammation of the supraspinous and supra-atlantal bursa. These syndromes are known as "fistulous withers" and "poll evil" respectively. The bursal sac becomes distended by clear, viscous, straw-colored exudates and develops a thickened wall. It can rupture, leading to a secondary point of infection.

Not all cases of poll evil and fistulous withers are associated with Brucella; other bacteria such as Streptococcus zooepidemicus may be involved. Brucella associated abortions are rare in horses. Other clinical signs reported in horses due $B$. abortus infection are arthritis, intermittent lameness, lethargy and swelling of carpal joint ${ }^{[64]}$.

\section{Brucellosis in dogs}

Brucella canis infection is one of the main infectious causes of reproductive disorders in wild and domestic dogs. The greatest prevalence rates probably occur among breeding dogs in commercial kennels where significant reproductive losses can be seen. Up to $75 \%$ fewer puppies

may be weaned from affected kennels according the hygienic and sanitary conditions ${ }^{[65]}$.

Clinical signs vary from asymptomatic to mild, despite an ongoing systemic infection. Morbidity is high but mortality is low. Bacteremia develops within two to three weeks after infection; the incubation period to clinical reproductive signs is variable ${ }^{[66]}$.

The classic sign of canine brucellosis is late abortion, which can occur between 30-57 days of gestation, being more common from 45 to 55 days of gestation in about $75 \%$ of the cases. Abortions are followed by mucoid, serosanguineous, brownish or gray vaginal discharge that persists for up to six weeks ${ }^{[66]}$. Brucellosis does not change the presentation of estrus and breeding ${ }^{[66]}$. The infected female can produce consecutive abortions and present litters of sick-born pups that die a few hours to more than one month after delivery. Birth of apparently normal offspring who develop the disease later can occur [67]. Abortions, premature litters and conception failures are observed in infected kennels ${ }^{[65,68]}$.

Resorption or early embryonic death within 2 to 3 weeks after breeding can also occur ${ }^{[66]}$. The female is considered infertile since no outward signs of fetal death were seen. Pups are lost as early as 20 days or are carried nearly to term. Infected bitches may deliver a normal litter the next pregnancy or give birth to living, partly autolyzed, stillborn and normal pups that die within hours. The surviving pups are bacteremic for a minimum of several months ${ }^{[66]}$, other congenitally infected pups can be born normal and later develop brucellosis. Some pups have transient fever, leukocytosis or seizures as manifestations of systemic infection. The bitch can abort two to three litters consecutively, continue to be bred and have a normal litter later [66]. Clinical signs can occur during subsequent pregnancies in some dogs but not in all of them [66]

B. canis targets androgen-dependent organs in the infected dog. The main clinical manifestations in males are severe epididymitis, orchitis and prostatitis. Epididymitis usually begins 5 weeks after infection. Acute onset of inflammation with pain and swelling enables the physical examination detection of orchitis and epididymitis. During the acute phase, the epididymis increases in size, accompanied by pain and presence of serosanguineous fluid in the tunica. Scrotal dermatitis develops from a constant licking by the male leading to edema and dermatitis which usually presents secondary contamination by non-hemolytic staphylococci ${ }^{[66]}$. Dogs with brucellosis may recover spontaneously as soon as one year after infection, but recovery is more common after 2 to 3 years after it, and some dogs remain chronically infected for at least five years ${ }^{[66]}$. Cats are relatively resistant to Brucella infections.

\section{In other species}

Bison, elk, reindeer and caribou can be infected with Brucella spp., but their role in transmission of the infections to livestock remains under debate ${ }^{[3]}$.

Most recently, Brucella spp. (different from those in land mammals) were isolated from dolphins, seals and an otter. Experimentally, at least one of the marine mammal species can infect and cause abortion in cattle, and marine mammal species have also been isolated from human beings ${ }^{[2]}$.

\section{Brucellosis in humans}

B. abortus, B. melitensis, B. suis, B. canis, and marine mammal Brucella species are human pathogens ${ }^{[2,}{ }^{4]}$. In humans, brucellosis can be a serious, debilitating and sometimes chronic disease that may affect a variety of organs [30]. Most cases are caused by occupational exposure to infected animals or the ingestion of unpasteurized dairy products ${ }^{[4,8]}$. 
Complications and involvement of internal organs can be diverse, depending on the site of infection, and include encephalitis, meningitis, spondylitis, arthritis, endocarditis, orchitis, and prostatitis [44]. Although unusual, spontaneous abortions have been seen in pregnant women infected with Brucella in early stages ${ }^{[49]}$.

\section{Laboratory diagnosis}

Culture from the blood of an animal provides definite proof of brucellosis ${ }^{[69]}$. Blood may be cultured using the biphasic method of Castaneda which uses both a solid and a liquid medium in the same container ${ }^{[70]}$. This method circumvents the need for subculturing and is used to limit the risk of laboratory-acquired infections. Brucella however, is a slow growing organism and cultures are rarely positive before the fourth day of incubation. Usually cultures become positive between the first and third week, and should be kept for at least 45 days before the culture can be concluded to be negative for Brucella. The modern semi-automatic culture systems have somewhat improved the speed of detection but are still too slow to make a fast diagnosis. Another improvement which one might consider is the identification of the organism in positive blood cultures by a modification of the cold ZN staining ${ }^{[71]}$. Because of the slowness of culture one often moves to serology ${ }^{[72]}$. Most serological tests rely on the unique antigenic properties of LPS that are shared among the Brucella species. The use of LPS as antigen causes cross reactivity with organisms such as Vibrio and Yersinica enterocolitica that share common features of the LPS ${ }^{[73]}$. More important in the use and interpretation of LPS based testing is the fact that in endemic areas a large proportion of the population may have developed antibodies due to previous disease or exposure.

The classical Rose Bengal test (RB) is often used as a rapid screening test ${ }^{[74]}$. RB is based on the agglutination of serum antibodies with a stained whole cell preparation of killed Brucella. The sensitivity of RB is very high (>99\%) but the specificity can be disappointingly low ${ }^{[75]}$. As a result, the positive predictive value of the test is low and a positive test result thus requires confirmation by a more specific test. The negative predictive value of $\mathrm{RB}$ though is high and a negative test results excludes active brucellosis with a high degree of certainty. To increase the specificity and the positive predictive value of $\mathrm{RB}$ the test may be applied to a serial dilution $(1: 2$ through $1: 64)$ of the serum sample. The specificity of the RB increases when higher dilutions agglutinate and titres of $1: 8$ or $1: 16$ and above may be regarded as positive. This approach however inevitably results in a lower sensitivity.

For confirmation of RB the Wright or serum agglutination test (SAT) or in more sophisticated equipped laboratories enzyme linked immunosorbent assay (ELISA) may be used [75, 76]. SAT is performed by mixing serial dilutions of serum, usually 1:20 through 1:2,560, with Brucella antigen in test tubes or in wells of an ELISA plate. After overnight incubation agglutination is readeither by the unaided eye or under a binocular. As guidance agglutination at titres of 1:160 or above is considered of diagnostic value as long as the animals have signs and symptoms of disease ${ }^{[75,76]}$.

Sometimes SAT is performed in the presence of the reducing agents 2-mercaptoethanol (2-ME) or dithiothreitol (DTT). These reducing agents destroy the agglutinating activity of immunoglobulin $\mathrm{M}(\mathrm{IgM})$ leaving $\operatorname{IgG}$ intact ${ }^{[72]}$. The $2-\mathrm{ME}$ or SAT-DTT test is used to increase the specificity of the reaction by looking at $\mathrm{IgG}$ only, which is important in animals with a more persistent infection.

In brucellosis, specific $\operatorname{IgM}$ antibodies dominate during the acute phase of the disease ${ }^{[77]}$. Specific IgG antibodies are present in the serum of animals at later stages of the illness and in the serum of relapsing animals ${ }^{[78]}$. ELISA is used to discriminate between the presence of specific $\operatorname{IgM}$ and $\mathrm{IgG}$ antibodies and to roughly access the stage of illness. SAT and the 2-ME test also are used for this purpose but are less accurate ${ }^{[78]}$.

\section{Treatment}

Uncomplicated acute brucellosis almost invariable responds well to appropriate antibiotic treatment $[79,80]$. To prevent disease progression and the development of complications, treatment should be start as early as possible also in animals showing signs of spontaneous improvement. The uncomplicated cases should be treated with doxycycline twice a day for 6 weeks plus streptomycin daily for 2 to 3 weeks. Instead of streptomycin rifampicin may be given in combination with doxycycline [81, 82]. Treatment of complications such as spondylitis and osteomyelitis, neurobrucellosis and brucella endocarditis may require prolonged therapy for at least 8 weeks. Other combinations such as co-trimoxazole plus doxycycline and co-trimoxazole plus rifampin have been proposed but still need further examination ${ }^{[81,82]}$. The optimal therapy for brucellosis during pregnancy has not been established ${ }^{[83]}$. Co-trimoxazole has been used successfully. Alternatively, rifampicin for at least 45 days may be used.

\section{Control and prevention of brucellosis in animals}

Mass vaccination is crucial for the control and eradication of bovine, ovine and caprine brucellosis but other complementary measures that may need consideration include improved farm hygiene, restriction and control of trade and movement of animals, testing of animals and isolation and removal of infected animals. Though the existing vaccine for bovine brucellosis, the B. abortus strain 19 (S19), and the vaccine for ovine and caprine brucellosis, the $B$. melitensis strain Rev 1, have some undesirable traits, these have proven to be very useful under most conditions ${ }^{[84-86]}$. Given the complexity of the epidemiology of brucellosis involving various animal species, the effective control will require a long lasting and carefully controlled and monitored effort. Therefore, preventive measures will be essential to minimize the risk of infection of the human population [87]. Such measures should include improved food hygiene including the pasteurization of milk and protection from infection of high risk groups such as milkers and other people working in the dairy industry. Health education of risk groups through community participation and health education programmes could play an important role to increase the acceptance and use of preventive measures ${ }^{[87-89]}$.

\section{Conclusion}

Brucellosis in animals and humans is worldwide distributed and being considered one of the most important zoonosis. It is a chronic disease and can develop several clinical forms, presenting from reproductive to systemic clinical signs and sometimes being asymptomatic. Affected symptomatic or asymptomatic animals represent important source of infection eliminating the agent through secretions and excretions. Humans are affected by contact with infected animals or through the ingestion of contaminated food. Marine species of 
Brucella have been recognized lately and there are reports of human infections with these species, demonstrating the wide range and adaptability of these bacteria.

\section{Reference}

1. Scholz HC, Hubalek Z, Nesvadbova J. Isolation of Brucella microti from soil. Emerg. Infect. Dis. 2008; 14:1316-7.

2. Sohn AH, Probert WS, Glaser CA, Gupta N, Bollen AW, Wong JD et al. Human neurobrucellosis with intracerebral granuloma caused by a marine mammal Brucella spp. Emerg. Infect. Dis. 2003; 9:485-488.

3. McDonald WL, Jamaludin R, Mackereth G, Hansen M, Humphrey S, Short P et al. Characterization of a Brucella sp. strain as a marine-mammal type despite isolation from a patient with spinal osteomyelitis in New Zealand. J. Clin. Microbiol. 2006; 44:4363-4370.

4. Hughes ML. Mediterranean, Malta or Undulant Fever. London, England: Macmillan and Co; 1897. Cited in: Evans AC. Comments on the early history of human brucellosis. In: Larson CH, Soule MH, eds. Brucellosis. Baltimore, Md: Waverly Press, Information Workshop, Ramallah, Palestine, 1950, 1-8p.

5. Meador VP, Hagemoser WA, Deyoe BL. Histopathologic findings in Brucella abortus-infected, pregnant goats. Am. J. Vet. Res. 1988; 49:274-280.

6. Nicoletti P. The epidemiology of bovine brucellosis. Adv. Vet. Sci. Comp. Med., 1980; 24:69-98.

7. Dewry RK, Islam K, Saikia GK, Hazarika SB, Deori S, Talukdar DJ. A case of brucellosis in a Jersey crossbred cow and its therapeutic management. In: Abstract \& Souvenir of $30^{\text {th }}$ Annual Convention of ISSAR, organised by College of Veterinary Science \& Animal Husbandry, DUVASU, Mathura, UP, India, 20-22, November, 2014, 67p.

8. Buchanan TM, Hendricks SL, Patton CM, Feldman RA. Brucellosis in the United States, 1960-1972: an abattoirassociated disease. Part III. Epidemiology and evidence for acquired immunity. Medicine (Baltimore). 1974; 53:427-439.

9. Ackermann MR, Cheville NF, Deyoe BL. Bovine ileal dome lymphoepithelial cells: endocytosis and transport of Brucella abortus strain 19. Vet Pathol. 1988; 25:28-35.

10. Braude AI. Studies in the pathology and pathogenesis of experimental brucellosis. In: The formation of the hepatic granuloma and its evolution. J. Infect. Dis. 1951; 89:8794.

11. Elsbach P. Degradation of microorganisms by phagocytic cells. Rev Infect Dis. 1980; 2:106-128.

12. Harmon BG, Adams LG, Frey M. Survival of rough and smooth strains of Brucella abortus in bovine mammary gland macrophages. Am J Vet Res. 1988; 49:1092-7.

13. Pizarro-Cerda J, Meresse S, Parton RG. Brucella abortus transits through the autophagic pathway and replicates in the endoplasmic reticulum of nonprofessional phagocytes. Infect Immun. 1998; 66:5711-5724.

14. Boschiroli ML, Ouahrani-Bettache S, Foulongne V. Type IV secretion and Brucella virulence. Vet Microbiol. 2002; 90:341-348.

15. Anderson TD, Cheville NF, Meador VP. Pathogenesis of placentitis in the goat inoculated with Brucella abortus. II. Ultrastructural studies. Vet Pathol. 1986; 23:227-239.

16. Anderson TD, Cheville NF. Ultrastructural morphometric analysis of Brucella abortus-infected trophoblasts in experimental placentitis: Bacterial replication occurs in rough endoplasmic reticulum. Am J Pathol. 1986; 124:226-237.

17. Capasso L. Bacteria in two-millennia-old cheese, and related epizoonoses in Roman populations. J. Infect. 2002; 45:122-127.

18. Godfroid J, Cloeckaert A, Liautard JP, Kohler S, Fretin $\mathrm{D}$, Walravens $\mathrm{K}$ et al. From the discovery of the Malta fever's agent to the discovery of a marine mammal reservoir, brucellosis has continuously been a reemerging zoonosis. Vet. Res. 2005; 36:313-326.

19. Shuaibi A. In: Palestinian brucellosis control programme. Country reports. Brucellosis, 1999,1-25p.

20. Anonymous. Brucellosis background. American Veterinary Medical Association. www.avma.org/public_health/brucellosis_bgnd.asp. Accessed on February 20, 2007.

21. Refai M. Incidence and control of brucellosis in the Near East region. Vet. Microbiol. 2002; 90:81-110.

22. Halling SM, Boyle SM. Incidence and control of brucellosis in the Near East region. Vet. Microbiol. 2002; 90:81-110

23. Jacques G, Kasbohrer A. Brucellosis in European Union and Norway at the turn of twenty first century. Vet. Microbiol. 2002; 90:135-145.

24. Renukaradhya GJ, Isloor S, Rajasekhar M. Epidemiology, zoonotic aspects,vaccination and control/eradication of brucellosis in India; Vet. Microbiol. 2002; 90:183-195

25. Chahota R, Sharma M, Katoch RC, Verma S, Singh MM, Kapoor $\mathrm{V}$ et al. Brucellosis outbreak in an organized dairy farm involving cows and in contact human beings, in Himachal Pradesh, India; Vet. Arh. 2003; 73:95-102

26. Mathur TN. Brucella strains isolated from cows, buffaloes, goats, sheep and human beings at Karnal: Their signifi cance with regard to the epidemiology of brucellosis; Indian J. Med. Res. 1964; 52:1231-1240

27. Mathur TN. The epidemiology of human brucellosis in Haryana with regard to 215 strains of brucella isolated from man and animals; Indian J. Pathol. Bacteriol. 1968; 11:244-249

28. Randhawa AS, Kalra DS, Kapur MP. Some seroepidemiologic observations on brucellosis in humans and animals; Indian J. Med. Sci. 1974; 28:133-138

29. Panjarathinam R, Jhala CI. Brucellosis in Gujarat state; Indian J. Pathol. Microbiol. 1986; 29:53-60

30. Thakur SD, Thapliyal DC. Seroprevalence of brucellosis in man; J. Commun. Dis. 2002; 34:106-109

31. Barbuddhe SB, Kumar P, Malika SV, Singh DK, Gupta LK. Seropositivity for intracellular bacterial infections among abattoir associated personnels; J. Commun. Dis. 2000; 32:295-299

32. Chadda VS, Soni PK, Gupta A, Gupta BK, Chadda S, Nayak KC. Incidence of brucellosis in arthritis and chronic low back pain in high risk group; J. Assoc. Physicians India. 2004; 52:338

33. Bandyopadhyay S, Sasmal D, Dutta TK, Ghosh MK, Sarkar M, Sasmal NK et al. Seroprevalence of brucellosis in yaks (Poephagus grunniens) in India and evaluation of protective immunity to S19 vaccine. Trop Anim Health Prod. 2009; 41:587-592.

34. Rajkhowa S, Rahman H, Rajkhowa C, Bujarbaruah KM. Seroprevalence of brucellosis in mithuns (Bos frontalis) in India. Preventive Veterinary Medicine. 2005; 69:145151. 
35. Lucero NE, Ayala SM, Escobar GI. Brucella isolated in humans and animals in Latin America from 1968 to 2008. Epidemiol. Infect. 2008; 136:496-503.

36. Chettri S, Ahmed K, Sarma DK, George S, Talukdar DJ, Deori S. Screening of bovine brucellosis by indirect ELISA in crossbred cows. In: Compendium, XII Annual Conference of IAVPHS, organised by College of Veterinary Science, Assam Agricultural University, Khanapara,Guwahati-22, Assam, 4-5 February, 2014, 262-3p.

37. Dafni I, Hoyda G, Feinhaken D. Observations on B. melitensis infection in israeli cattle herds. Israel $\mathbf{J}$ Vet Med. 1991; 46:13-9.

38. Manthei CA. Brucellosis in cattle. In: Brucellosis, a symposium. Washington, D.C., Am. Ass. Adv. Sci. 1950, 172-87p.

39. Crawford RP, Adams LG, Williams JD. Relationship of fetal age at conjunctival exposure of pregnant heifers and B. abortus isolation. Am. J. Vet. Res. 1987; 48:755-7.

40. Dewry RK, Islam K, Talukdar DJ, Deori S, Saikia B, Hazarika SB. Management of incomplete cervical dilatation during abortion in a cow. The Indian Journal of Animal Reproduction. 2015; 35(1):65-66.

41. Carpenter CM. Bacterium abortus invasion of the tissues of calves from the ingestion of infected milk. Cornell Vet. 1924; 14:16-31.

42. Bang B. Infectious abortion in cattle. J. Comp. Pathol. Ther. 1906; 19:191-202.

43. Thomsen A. Experimental studies on the incubation period of infectious abortion in cattle. Br. Vet. J. 1950; 106:41-5.

44. Acha NP, Szyfres B. In: Zoonoses and Communicable diseases common to man and animals, $3^{\text {rd }}$ ed. Pan American Health Organization (PAHO), Washington D.C. $2003 ; 1: 423$.

45. Emminger AC, Schalm OW. The effect of Brucella abortus on the bovine udder and its secretion. Am. J. Vet. Res. 1943; 4:100-9.

46. Schlafer DH, Miler RB. Female genital system. In: Maxie MG, Ed. Pathology of domestic animals. 5th ed. Elsevier Saunders: Philadelphia. 2007; 3:484-9.

47. Xavier MN, Paixao TA, Poester FP. Pathological, immunohistochemical and bacteriological study of tissues and milk of cows and fetuses experimentally infected with Brucella abortus. J. Comp. Pathol. 2009; 140:14957.

48. Wilesmith JW. The persistence of Brucella abortus infection in calves: A retrospective study of heavily infected herds. Vet. Rec. 1978; 103:149-53.

49. Edgington $\mathrm{BH}$, Donham CR. Infection and reinfection experiments with Bang's disease. J. Agric. Res. 1939; 59:609-18.

50. Buck JM, Creech TT, Ladson HH. Bacterium abortus infection of bulls. J. Agric. Res. 1919; 17:239-46.

51. Foster G, Osterman BS, Godfroid J. Brucella ceti sp. nov. and Brucella pinnipedialis sp. nov. for Brucella strains with cetaceans and seals as their preferred hosts. Int. J. Syst. Evol. Microbiol. 2007; 57:2688-93.

52. Lambert G, Manthei CA, Deyoe BL. Studies on B. abortus infection in bulls. Am. J. Vet. Res. 1963; 24:1152-7.

53. Paolicchi FA, Terzolo HR, Campero CM. Isolation of Brucella suis from the semen of a ram. Vet. Rec. 1993; 132:67
54. Smith T. Pneumonia associated with Bacillus abortus (Bang) in fetuses and new-born calves. J. Exp. Med. 1925; 41:639-48.

55. Lopez A, Hitos F, Perez A. Lung lesions in bovine fetuses aborted by B. abortus. Can. J. Comp. Med. 1984; 48:275-7.

56. Deyoe BL. Brucellosis. In: Leman AD, Straw B and Glock RD. Eds. Diseases of swine. 6th ed. Ames: Iowa State University Press, 1986, 599-607.

57. Gillespie JH, Timoney JF. Hagan and Bruner's infectious diseases of domestic animals. Cornell University Press: Ithaca, NY, 1981, 85.

58. Luchsinger DW, Anderson RK. Longitudinal studies of naturally acquired Brucella abortus infection in sheep. Am. J. Vet. Res. 1979; 40:1307-12.

59. Alton GG. B. melitensis. Animal Brucellosis. In: Nielsen \& Duncan, Eds. CRC Press: Boca Raton Florida, USA, 1990; 17:383-409.

60. Ahmed K, Dewry RK, Talukdar DJ, Mahanta N. Dystocia due to mummified foetus in a local goat of Assam. The Indian Journal of Small Ruminants. 2014; 20(1):138-139

61. Leon CF. Brucelosis ovina y caprina. Ed. Office International dês Epizooties - OIE. Paris: Francia. 1994, 451.

62. Cyetnic Z, Spicic S, Curic S. Isolation of B. suis biovar 3 from horses in Croatia. Vet. Rec. 2005; 156:584-5.

63. Millan MAP, Baskerville A, Ambleton P. Experimental B. abortus infection in the horse: observations during the three months following inoculation. Res. Vet. Sci. 1982; 33:351-9.

64. Ocholi RA, Bertu WJ, Kwaga JKP. Carpal bursitis associated with B. abortus in a horse in Nigeria. Vet. Rec. 2004; 155:566-7.

65. Megid J, Brito AF, Moraes CCG. Epidemiological assessment of canine brucellosis. Arq. Bras. Med. Vet. 1999; 51:439-40.

66. Hollett RB. Canine brucellosis: Outbreaks and compliance. Theriogenology, 2006; 66:575-87.

67. Wanke MM. Canine brucellosis. Anim. Reprod. Sci. 2004; 82-83:195-207.

68. Konwar B, Bayan H, Sarma K, Talukdar D. Management of foetal mummification in Canine. International Journal of Livestock Research. 2020; 10(3):212-217.

69. Al Dahouk S, Tomaso $H$, Nockler $K$, Neubauer $H$, Frangoulidis D. Laboratory-based diagnosis of brucellosis - a review of the literature Part I: Techniques for direct detection and identification of Brucella spp. Clin Lab. 2003; 49:487-505.

70. Mantur BG, Mangalgi SS. Evaluation of conventional castaneda and lysis centrifugation blood culture techniques for diagnosis of human brucellosis. J. Clin. Microbio. 2004; 42:4327-8.

71. Joshi PA, Kulkarni RD, Powar RM. Modified cold Z-N staining for presumptive identification of Brucella. Indian J. Med. Res. 2005; 121:108-10.

72. Al Dahouk S, Tomaso H, Nockler K, Neubauer H, Frangoulidis D. Laboratory-based diagnosis of brucellosis - a review of the literature. Part II: serological tests for brucellosis. Clin. Lab. 2003; 49:577-89.

73. Munoz PM, Marin CM, Morreal D, Gonzales D, GarinBastuji B, Diaz R. Efficacy of several serological tests and antigens for diagnosis of bovine brucellosis in the presence of false-positive serological results due to 
Yersinia enterocolitica O:9. Clin. Diag. Lab. Immunol. 2005; 12:141-51.

74. Ruiz-Mesa JD, Sanchez-Gonzalez J, Reguera JM, Martin L, Lopez-Palmero S, Colmenero JD. Rose Bengal test: diagnostic yield and use for the rapid diagnosis of human brucellosis in emergency departments in endemic areas. Clin. Microbiol. Infect. 2005; 11:221-5.

75. Kiel FW, Khan MY. Analysis of 506 consecutive positive serologic tests for brucellosis in Saudi Arabia. J. Clin. Microbiol. 1987; 25:1384-7.

76. Mathai E, Singhal A, Verghese S, D'Lima D, Mathai D, Ganesh A. Evaluation of an ELISA for the diagnosis of brucellosis. Indian J. Med. Res. 1996; 103:323-4.

77. Smits HL, Abdoel TH, Solera J, Clavijo E, Diaz R. Immunochromato graphic Brucella-specific immunoglobulin $\mathrm{M}$ and $\mathrm{G}$ lateral flow assays for rapid serodiagnosis of human brucellosis. Clin. Diagn. Lab. Immunol. 2003; 10:1141-6.

78. Ariza J, Pellicer T, Pallares R, Foz A, Gudiol F. Specific antibody profile in human brucellosis. Clin. Infect. Dis. 1992; 14:131-40.

79. Solera J, Martinez-Alfaro E, Espinosa A. Recognition and optimum treatment of brucellosis. Drugs. 1997; 53:245-56.

80. Solera J. Treatment of human brucellosis. J. Med. Liban. 2000; 48:255-63.

81. Bayindir Y, Sonmez E, Aladag A, Buyukberber N. Comparison of five antimicrobial regimens for the treatment of brucellar spondylitis: a prospective, randomized study. J. Chemother. 2003; 15:466-71.

82. Roushan MR, Gangi SM, Ahmadi SA. Comparison of the efficacy of two months of treatment with co-trimoxazole plus doxycycline vs. co-trimoxazole plus rifampin in brucellosis. Swiss Med. Wkly. 2004; 134:564-8.

83. Young EJ. Brucella species (Brucellosis). In: Yu VL, Weber R, Raoult D, editors. Antimicrobial, therapy and vaccines. Vol. I: Microbes. New York, USA: Apple Tree Productions, LLC, 2003, 121-40.

84. Minas A, Minas M, Stournara A, Tselepidis S. The "effects" of Rev-1 vaccination of sheep and goats on human brucellosis in Greece. Prev. Vet. Med. 2004; 64:41-7.

85. Moriyon I, Grillo MJ, Monreal D, Gonzalez D, Marin C, Lopez-Goni I. Rough vaccines in animal brucellosis: structural and genetic basis and present status. Vet. Res. 2004; 35:1-38.

86. Schurig GG, Sriranganathan N, Corbel MJ. Brucellosis vaccines: past, present and future. Vet. Microbiol. 2002; 90:479-96.

87. Bruce D. Note on the discovery of a micro-organism in Malta fever. Practitioner (London). 1887; 39:161-170. Cited in: Evans AC. Comments on the early history of human brucellosis. In: Larson $\mathrm{CH}$, Soule $\mathrm{MH}$, eds. Brucellosis. Baltimore, Md: Waverly Press, 1950, 1-8.

88. Bracewell CD, Corbel MJ. An association between arthritis and persistent serological reactions to B. abortus in cattle from apparently brucellosis-free herds. Vet. Rec. 1980; 106:99-101.

89. Foster RA, Ladds PW. Male genital system. In: Maxie MG, Ed. Pathology of Domestic Animals. 5th ed. Elsevier Saunders: Philadelphia, 2007; 3:565-619. 